\title{
PROVOCAÇÕES PÓS-COLONIAIS À FORMAÇÃO EM PSICOLOGIA
}

\author{
PROVOCACIONES POSTCOLONIALES \\ A LA FORMACIÓN EN PSICOLOGÍA \\ POST-COLONIAL PROVOCATIONS \\ TO THE EDUCATION IN PSTCHOLOGX
}

\author{
Jailleilla Araújo Menezes ${ }^{1}$, Saiane Silva Lins $^{2}$ e \\ Juliana Vieira Sampaio ${ }^{2}$ \\ ${ }^{1}$ Universidade Federal de Pernambuco, Recife/PE, Brasil \\ ${ }^{2}$ Universidade Federal do Ceará, Fortaleza/CE, Brasil
}

RESUMO: Tendo como referência os estudos pós-coloniais e suas críticas ao norte-centrismo, sexismo e racismo na produção científica, buscamos nesse artigo apresentar a experiência da oficina Racismo, Sexismo, Epistemicídios e os saberes Psi, que aconteceu durante a XXVI Semana de Psicologia da Universidade Federal do Ceará. Nesse contexto, promovemos o debate sobre como o eurocentrismo epistêmico, o racismo e o sexismo produzem efeitos no campo de saber da Psicologia e discutimos com estudantes de graduação e pós-graduação estratégias de resistência cientificamente engajadas no enfrentamento das injustiças sociais. Na medida em que questionamos a objetividade, neutralidade e universalidade da ciência, também colocamos em discussão a naturalização da desigualdade e exclusão social. O exercício de decolonialidade proposto na oficina teve uma dimensão de provocação denunciativa das violências epistêmicas que nos constituem e imaginativa das transformações que temos de realizar para acolher a diversidade epistêmica em um mundo pluriversal.

PALAVRAS-CHAVE: Estudos pós-coloniais; Produção científica; Formação em Psicologia; Racismo; Sexismo.

RESUMEN: Tomando como referencia los estudios postcoloniales y sus críticas al nortecentrismo, sexismo y racismo en la producción científica, buscamos en este artículo presentar la experiencia del taller Racismo, Sexismo, Epistemicidios y los saberes Psi, que ocurrió durante la XXVI Semana de Psicología de la Universidade Federal do Ceará. En ese contexto promovemos el debate sobre cómo el eurocentrismo epistémico, el racismo y el sexismo producen efectos en el campo de saber de la Psicología y discutimos con estudiantes de graduación y postgrado estrategias de resistencia científicamente comprometidas en el enfrentamiento de las injusticias sociales. A medida que cuestionamos la objetividad, neutralidad y universalidad de la ciencia, también ponemos en discusión la naturalización de la desigualdad y exclusión social. El ejercicio de decolonialidad propuesto en el taller tuvo una dimensión de provocación denunciante de las violencias epistémicas que nos constituyen y imaginativa de las transformaciones que tenemos que realizar para acoger la diversidad epistémica en un mundo pluriversal.

PALABRAS CLAVE: Estudios postcoloniales; Producción científica; Formación en Psicología; Racismo; Sexismo.

ABSTRACT: Having as reference the post-colonial studies and its critics towards the North-centrism, sexism and racism in the scientific production, we intend to present in this article the experience from the workshop Racism, Sexism, Epistemicide and the Psi knowledges, which took place during the XXVI Psychology Week of Federal University of Ceará. In this context we promoted the debate about how the epistemic eurocentrism, the racism and the sexism produce effects in the field of knowledge of Psychology and discussed with students from the undergraduate and graduate programs the resistance strategies scientifically engaged in the confrontation of social injustices. As long as we query objectivity, neutrality and the universality of science, we also bring to discussion the naturalisation of social inequality and exclusion. The exercise of decoloniality as proposed in the workshop had a dimension of denunciatory provocation concerning the epistemic violences which constitute ourselves, as well as of an imaginative one concerning the transformations we have to make so that we welcome epistemic diversity in a pluriversal world. KEYWORDS: Post-colonial studies; Scientific Production; Education in Psychology; Racism; Sexism. 


\section{Introdução}

A Psicologia como profissão foi regulamentada em 1962, pela Lei n. 4.119/1962, e desde então o Ministério da Educação (MEC) institui as Diretrizes Curriculares Nacionais para formação dos futuros psicólogos, estabelecendo normas para o projeto pedagógico dos cursos de graduação. Nesse cenário os cursos de Psicologia definem quais os conteúdos, perspectivas teóricas, políticas e éticas irão fundamentar a formação de seus estudantes, tendo como orientação as diretrizes do MEC, mas também possuem determinada autonomia.

Entendemos que as escolhas de conteúdos e autores para a composição curricular é uma decisão política, que produz efeitos diversos, como a manutenção e a cristalização de práticas de colonialidade do saber ou a pluralidade epistêmica (Castro-Gomez, 2005), conceitos que trataremos adiante. Os autores escolhidos compõem os currículos dos cursos de Psicologia e constituem a rede de produção, circulação, ordenação e consolidação do saber-poder desta área de conhecimento, agenciando modos de ser psicólogo. Dessa forma, mapear os referentes teóricos que contribuem para estabelecer a Psicologia como ciência e profissão ajuda-nos a visualizar o espaço de lutas e os jogos múltiplos que a colonialidade do saber produz.

O termo "colonialidade do saber" faz referência a herança de eurocentrismo epistemológico que limita a nossa compreensão de mundo aos saberes produzidos por homens brancos ocidentais, em especial os pertencentes a cinco países: França, Alemanha, Inglaterra, Estados Unidos e Itália. Essa dinâmica de produção de conhecimento ao mesmo tempo que privilegia determinados lugares de fala, supostamente neutros e objetivos, também desvaloriza os saberes daqueles que estão ao sul do globo, não brancos e mulheres. Os homens reconhecidos pela estrutura colonial monopolizam a definição do que é o conhecimento verdadeiro e em articulação com as dimensões de colonialidade do poder e colonialidade do ser estabelecem, a partir de seus referentes, o que é o melhor para o restante da humanidade.

A violência colonial foi física e epistemológica e apesar da colonização strictus sensu ter acabado, ficaram seus efeitos em termos de padrão cultural branco/europeu como organizador do mundo, da vida e do pensamento. A racionalidade europeia originária do iluminismo ainda respinga seus resquícios sobre nós e continua a impor um projeto colonial que envolve aspectos econômicos, políticos, sociais, cognitivos e subjetivos.

Segundo Grosfoguel (2016), o eurocentrismo, o racismo e o sexismo epistêmico compõem um campo de problemas importantes do mundo contemporâneo, pois tais posturas silenciam os saberes produzidos por outros corpos geopoliticamente localizados na periferia dos centros de referência ocidentalizados. Entendemos que questionar nossas estruturas de conhecimento colabora para o processo de descolonização das nossas subjetividades e no enfrentamento das injustiças cognitivas através da elaboração de outras narrativas pautadas nos saberes e fazeres de povos historicamente desqualificados enquanto produtores de conhecimento.

A estruturação e institucionalização do eurocentrismo, do racismo e do sexismo epistêmico calam as vozes que questionam o modelo de ciência da modernidade que defende o saber neutro, objetivo e universal. Castro-Gomes (2005) analisa que o "projeto" da modernidade estabelece a racionalidade como eixo central de compreensão do mundo. 
Neste contexto, a Universidade é reconhecida como espaço privilegiado de produção de conhecimento em uma perspectiva arbórea, na qual ocorre uma hierarquização, estabelecimento de limites, diferenciação e fronteiras epistêmicas que não devem ser cruzadas (Castro-Gomes, 2005).

O processo de produção de conhecimento dentro da Universidade envolve a eleição de determinados autores para serem trabalhados ao longo da graduação. Essa lista, de modo geral, envolve teóricos classificados como clássicos e autoridades em determinadas temáticas. Nesse processo cabem alguns questionamentos: quem elege os clássicos e a partir de quais perspectivas e realidades? Como os clássicos são utilizados, considerando as (im)possibilidades de diálogo, limites e confrontações entre o contex to de produção da teoria e a realidade que circunscreve as condições de vida de psicólogos em formação? Ao privilegiar os clássicos em uma perspectiva colonial, quais saberes são silenciados, desprezados por serem categorizados como não científicos, atrasados, mitológicos e anedóticos? A Universidade, quando não realiza a revisão crítica contextualizada de seus currículos, contribui para a reiteração do epistemicídio, ou seja, da violência que destrói e invisibiliza a diversidade epistemológica e a contribuição de grupos sociais historicamente subalternizados (Santos, Meneses, \& Nunes, 2004).

Tendo como referência os estudos pós-coloniais e suas críticas ao norte-centrismo, sexismo e racismo na produção científica, buscamos nesse artigo apresentar a experiência da oficina "Racismo, Sexismo, Epistemicídios e os saberes Psi", que aconteceu durante a XXVI Semana de Psicologia da Universidade Federal do Ceará, com o tema "Teorias e Práticas: Psicologia de Lattes e de Luta?”. Nesse contexto, promovemos o debate sobre como o eurocentrismo epistêmico, o racismo e o sexismo produzem efeitos no campo de saber da Psicologia e discutimos estratégias de resistência cientificamente engajadas no enfrentamento das injustiças sociais. Na medida em que questionamos a objetividade, neutralidade e universalidade da ciência, também colocamos em discussão a naturalização da desigualdade e exclusão social.

\section{Método}

A oficina Racismo, Sexismo, Epistemicídio e os Saberes Psi, que apresentamos neste trabalho, fez parte da programação da XXVI Semana de Psicologia da Universidade F. do Ceará, e teve como objetivo suscitar discussões que geralmente não ganham visibilidade no referido curso. O tema da Semana, “Teorias e Práticas: Psicologia de Lattes e de Luta?”, também buscou pautar inquietações no tocante ao fazer político em articulação à produção de conhecimento da área de Psicologia.

Durante o evento, as oficinas dispunham de 2 horas, e foram selecionadas previamente para integrar a programação geral do evento - através de formulário online para envio de propostas de oficinas e avaliação pela organização do evento. Cada participante do evento se dirigia, ao longo da Semana de Psicologia, para as atividades da programação de acordo com os seus interesses. Nesse contexto, a oficina que aqui tratamos teve como objetivo interrogar a construção do conhecimento científico, em especial os/as autores/as de referência em Psicologia, e discutir: quem detém o privilégio na produção desse conhecimento? que parte do globo possui poder epistêmico e quais as consequências disso para quem está de fora desse círculo de legitimidade científica? 
Seguimos um roteiro que contemplou: apresentação dos/das participantes e dos objetivos da oficina; dinâmica de aquecimento; atividade para conhecer quais autores(as) eram mais trabalhados pelos(as) participantes durante sua formação em Psicologia; discussão e, a partir daí, produção de material com a sistematização de sugestões para o currículo do curso de Psicologia.

Usamos como material: canetas piloto, papel ofício, papel madeira, canetinhas coloridas, caixa pequena, notebook, projetor e papel-adesivo. Também organizamos uma lista de músicas latino-americanas para embalar nossa oficina, com temas sobre racismo e sexismo.

Participaram da oficina sete estudantes, sendo seis da graduação (quatro do primeiro período, um do segundo e um do décimo período) e uma estudante da pós-graduação (doutorado). As facilitadoras da oficina (duas com doutorado em Psicologia e uma estudante do oitavo semestre do curso) também se posicionaram como participantes, realizando junto com o grupo as atividades propostas. A condição de facilitadoras-participantes (Adrião \& Menezes, 2017) colaborou para a construção de um solo comum de experiências (tempo-espaço da oficina) entre pessoas com percursos acadêmicos diferenciados, diluiu o receio de ocupar um lugar de fala, pois fez a palavra circular sem tom avaliativo e pedagogizante. A posição de facilitadoras-participantes expressou a intencionalidade do nosso questionamento à produção do conhecimento crítico em Psicologia (dimensão de intervenção/ transformação que a oficina buscou operar), através da produção coletiva.

Para o momento inicial de aquecimento do grupo, propomos uma atividade inspirada na técnica "Coisas em comum” (McCarthy \& Galvão, 2001, pp. 54-55), que consistia em conversar de modo intencionado para encontrar três interesses/gostos em comum e uma opinião divergente sobre algum assunto polêmico, como, por exemplo, temas banais e cotidianos (ter tatuagem, gostar ou não de passas no arroz) e posicionamento sobre a descriminalização do aborto e sobre a patologização das identidades trans, etc.

Na sequência, passamos à atividade de construção do mapa teórico. Solicitamos que cada participante apontasse até cinco teóricos/as que contribuíram no seu percurso formativo em Psicologia, até então. Logo após, em um mapa-múndi projetado no quadro branco, registramos os nomes dos autores e das autoras a partir do local em que nasceram, fazendo também o destaque dos marcadores de gênero e raça/etnia.

Finalizado o mapa teórico, a própria disposição físico-geográfica dos resultados encontrados já foi disparadora do debate. Também utilizamos como recurso para nortear os aspectos teórico-críticos da discussão algumas frases extraídas do texto de Ramón Grosfogel (2016), que foram depositadas em uma caixa. Cada participante retirou uma frase para ler, comentar e destacar aspectos da geografia política, racista e misógina de nossas referências teóricas.

Para buscar formas de materializar as inquietações e as demandas geradas na discussão, construímos algumas propostas para serem discutidas nos momentos de reformulação curricular da formação em Psicologia da UFC - aproveitando que o curso se encontrava no momento de construção de um nova proposta de seu Projeto Pedagógico -, então registramos em cartazes e encaminhamos para subsidiar as reuniões do Centro Acadêmico e da comissão de reforma curricular. 


\section{Resultado e discussão}

Ao contabilizarmos as respostas à provocação "Escreva até 5 teóricos/as que contribuíram até então no seu percurso formativo em Psicologia”, obtivemos as seguintes menções, com número total de ocorrências: Michel Foucault (9), Judith Butler (4), Sigmund Freud (4), Zygmunt Bauman (4), Ângela Davis (3), Carl G. Jung (2), Hanna Arendt (2), Karl Marx (2), Paul B. Preciado (2), Burrhus Frederic Skinner (1), David Harvey (1), Flavia Biroli (1), Lúcia Rabello (1), Mary Jane Spink (1), Nikolas Rose (1), Paul Ricouer (1) e Sueli Carneiro (1).

Inicialmente, o que nos chama atenção nesse exercício foi o significativo número de citações a Michel Foucault, filósofo francês que nasceu na década de 20 e faleceu na década de 80 do século passado, reconhecido como um dos autores mais influentes da contemporaneidade. Sua vasta obra é comumente citada a partir da composição de três grandes eixos de preocupação ou domínio: a arqueologia, a genealogia e os estudos sobre a ética do cuidado de si e em todos eles se configura uma articulação específica entre saber-poder-verdade e seus efeitos de produção de sujeito (Figueiredo, 1995).

Pensar o efeito Foucault no campo psi é considerar sua importante contribuição em termos de um movimento crítico à ciência psicológica que se constitui, segundo as reflexões arqueológicas do autor, no espaço híbrido e ambíguo entre a filosofia e as ciências naturais. Em seus estudos genealógicos, Foucault enfatiza as contribuições das práticas psicológicas através do exercício das técnicas disciplinares, para o estabelecimento de princípio de normalidade fundamentais à produção da alteridade que deverá ser encarcerada e/ou terapeutizada. Como observam Ferreira, Moreira, Araújo e Drawin (2017), "a abordagem política de Foucault está em sintonia com a multiplicidade das lutas transversais, nas quais o tema da subjetividade ganha destaque" (p. 7).

Por outro lado, nos trabalhos sobre a ética do cuidado de si como obra de arte, o autor delineia aspectos que podem inspirar práticas psicológicas pautadas na coragem de verdade onde os/as profissionais psi tomariam como princípio de sua ação profissional a potencialização da vida e não a ortopedia moral das condutas desejáveis em sociedades capitalistas e neoliberais.

Com essa expressividade das referências a Foucault, como também observam, em trabalho recente, Ferreira et al. (2017) sobre o uso do referido autor em artigos na área da Psicologia, para nós surge a questão de como situá-lo - para além das contribuições críticas ao saber e prática psicológica - no debate sobre Racismo, Sexismo, Epistemicídio. No campo dos estudos pós-coloniais, particularmente considerando as reflexões de Gayatri Spivak (2010), em sua obra Pode o subalterno falar?, Foucault seria um intelectual alinhando com a perspectiva da representação, ou seja, em seu exercício crítico ele acaba assumindo o lugar do outro, ao invés de se comprometer em criar condições para que o subalterno fale e com isso possa ser ouvido. Em assim agindo, acaba produzindo a violência epistêmica, ou seja, a impossibilidade de auto representação de sujeitos silenciados pelo imperialismo, dos quais nunca se encontra o testemunho de sua voz (Almeida, 2010). Nessa perspectiva, o efeito Foucault na Psicologia seria um obstáculo epistemológico à produção de uma crítica pós-colonial nesse campo de saber-poder. 
Santiago Castro-Gomez (2007), filósofo colombiano que integra o grupo modernidade/colonialidade, em seu texto Michel Foucault y la colonialidad del poder, retoma a crítica de Spivak (2010) ao filósofo francês sobre a sua microfísica do poder trabalhar em prol de ocultar e legitimar a macrofísica do poder. Para Castro-Gomez (2007), há um desconhecimento dos/das críticos/as de Foucault com relação ao seu método, pois consideram o poder como fenômeno maciço e homogêneo, ao contrário de Foucault, que o analisa como algo que funciona em muitas direções e em cadeia.

Se por um lado Castro-Gomez (2007) advoga que a analítica foucaultiana do poder é uma metodologia eurocêntrica do ponto de vista do conteúdo, isso não recobre sua forma, pois tem potencial para ser utilizada como metodologia válida de análise sobre a complexidade do sistema-mundo e acerca da relação entre modernidade e colonialidade. Nesse sentido, as reflexões sobre racismo presentes nos cursos biopolítica e governamentalidade (Foucault, 2010) expressam bem o entendimento do filósofo francês acerca das relações de poder e da funcionalidade dos dispositivos e tecnologias biopolíticas na construção dos estados nação modernos.

Foucault se interessa pelo racismo como formação discursiva e dispositivo estatal para justificar ações com relação à populações indesejadas no interior das fronteiras da Europa. A experiência colonial europeia colaborou para desenvolver o discurso do racismo, mas não é igual ao racismo intraeuropeu, assim: "el racismo es una formación discursiva que se vincula con diversos contextos de guerra social y circula por diferentes cadeias de poder" (Castro-Gomez, 2007, p. 159).

O poder não é monolítico, o racismo não é homogêneo e a colonialidade não se reduz ao que as potências hegemônicas do sistema-mundo impõe aos territórios da periferia. Há que se visibilizar os dispositivos de regulação e normatização que operam na dimensão governamental, as tecnologias de resistência e as possibilidades de decolonização em uma perspectiva molecular. Nesse plano de atenção/tensão, Foucault teria muito a contribuir para a crítica à colonialidade dos saberes psi.

Um segundo olhar sobre os resultados de nosso mapa teórico mostra-nos que, se por um lado as referências aos gêneros clássicos são aproximadas - 7 mulheres, 9 homens -, o não-binário teve duas indicações (Paul B. Preciado). O contraste racial, por sua vez, foi bastante evidente, sendo 15 referências a teóricos/as brancas e apenas a 2 negras. Ângela Davis e Sueli Carneiro são intelectuais contemporâneas e emblemáticas do pensamento crítico feminista negro. Embora habitando espaços geográficos diferentes e desiguais entre si, ambas falam de suas experiências de violação de direitos tendo como referência o acontecimento da escravidão, que qualifica o racismo em seus contextos existenciais e destaca os efeitos ainda fortemente operantes.

Particularmente para Sueli Carneiro (2003) - filósofa, escritora e ativista do movimento social negro brasileiro - o mito da democracia racial produzido em nosso país mantém intactas as relações de gênero segundo a cor ou a raça instituídas no período da escravidão. A autora ressalta as condições históricas que desde a violação colonial tem produzido a coisificação e objetificação das mulheres negras. O racismo figura assim como principal eixo articulador da opressão, com impactos sobre a hierarquia de gênero, que dificulta sobremaneira às mulheres negras o acesso à condições plenas em possibilidades e oportunidades de vida. 
"Mais autores negros" e "Dê voz acadêmica aos negros periféricos" foram duas demandas escritas nos cartazes de sistematização do debate ocorrido na oficina e endereçado aos fóruns de discussão para a reforma do projeto político-pedagógico do curso de Psicologia da Universidade Federal do Ceará. Sueli Carneiro (2003) traz a referência do poeta negro Aimé Cesaire sobre as duas maneiras de perder-se: por segregação, sendo enquadrado na particularidade, ou por diluição no universal. Trazendo essa reflexão para o campo de formação de psicólogos/as há que se produzir alternativas aos procedimentos de redução da dimensão humana e à reiteração da universalidade ocidental hegemônica que, além de anular a diversidade, anula também a voz-testemunho dos/das que vivenciam desigualdades sociais.

O exercício de crítica à colonialidade proposto na oficina "Racismo, Sexismo, Epistemicídio e os Saberes Psi" teve uma dimensão de provocAção denunciativa das violências epistêmicas que nos constituem, e imaginativa das transformações que temos de realizar para acolher a diversidade de (re)conhecimentos em um mundo pluriversal. Sendo assim, com a palavra final as demandas dos/das participantes da oficina, que foram posteriormente apresentadas em cartazes nas reuniões sobre a reforma curricular: "LGBTs falando sobre LGBTs"; "Bolsa por critérios socioeconômicos (sem ser por meritocracia)"; "não ter limite de créditos livres na graduação"; "Grades Curriculares?”; "Abordar autoras não ocidentais"; "Novas metodologias de aprendizagem que não hierarquizem a construção dos saberes"; "Aulas Vivenciais!".

\section{Referências}

Adrião, K. G. \& Menezes, J. A. (2017). Perspectivas teórico-metodológicas do curso de formação em mídias móveis: o recurso audiovisual como dispositivo para participação política juvenil. In J. A. Menezes, K. G. Adrião, \& L. F. Rios (Orgs.), Jovens, câmera, ação: reflexões sobre os usos dos dispositivos móveis de mídia em um projeto de mobilização social (pp 16-41). Recife: Editora UFPE. Almeida, S. R. G. (2010). Prefácio - Apresentando por Spivak. In Pode o subalterno falar? (pp. 7-18). Belo Horizonte: Editora UFMG.

Carneiro, S. (2003). Enegrecer o feminismo: a situação da mulher negra na América Latina a partir de uma perspectiva de gênero. In Ashoka Empreendimentos Sociais \& Takano Cidadania (Orgs.), Racismos contemporâneos (pp. 49-58). Rio de Janeiro: Takano.

Castro-Gómez, S. (2005). Ciências sociais, violência epistêmica e o problema da "invenção do outro”. In E. Lander (Org.), A colonialidade do saber: eurocentrismo e ciências sociais. Perspectivas latino-americanas (pp. 80-87). Buenos Aires: CLACSO Consejo Latinoamericano de Ciencias Sociales.

Castro-Gómez, S. (2007). Michel foucault y la colonialidad del poder. Tabula Rasa, 6, 153-172. Recuperado de http://www.redalyc.org/pdf/396/39600607.pdf

Ferreira, J. L., Moreira, J. O., Araújo, J. N. G., \& Drawin, C. R. (2017). Usos de Foucault nos estudos de Psicologia no Brasil. Psicologia E Sociedade, 29, e159930. Recuperado de http://www. scielo.br/pdf/psoc/v29/1807-0310-psoc-29-e159930.pdf

Figueiredo, L. C. (1995). Foucault e Heidegger. A ética e as formas históricas do habitar (e do não habitar). Tempo Social, 7(1-2), 136-149. Recuperado de http://dx.doi.org/10.1590/ ts.v7i1/2.85214 
Foucault, M. (2010). Aula de 17 de março de 1976. Em defesa da sociedade: curso no Collége de France (1975-1976) (M. E. Galvão Trad., 2a. ed.). São Paulo: Martins Fontes.

Grosfoguel, R. (2016). A estrutura do conhecimento nas universidades ocidentalizadas: racismo/sexismo epistêmico e os quatro genocídios/epistemicídios do longo século XVI. Sociedade e Estado, 31(1), 25-49. Recuperado de http://www.scielo.br/pdf/se/v31n1/0102-6992se-31-01-00025.pdf,

Lei nº 4.119, de 27 de agosto de 1962. Dispõe sôbre os cursos de formação em psicologia e regulamenta a profissão de psicólogo. Brasília, DF, 14 dez. 1962. Recuperado de http://www.planalto.gov.br/ccivil_03/leis/1950-1969/14119.htm.

McCarthy, J. \& Galvão, K. (2001). Projeto Artpad: Um recurso para teatro, participação e desenvolvimento. Recife: Artpad.

Santos, B. S., Meneses, M. P., \& Nunes, J. A. (2004). Introdução: para ampliar o cânone da ciência: a diversidade epistemológica do mundo. In B. S. Santos (Ed.), Semear outras soluções: os caminhos da biodiversidade e dos conhecimentos rivais (pp 19-101). Porto, PT: Edições Afrontamento.

Spivak, G. (2010). Pode o subalterno falar? Belo Horizonte: UFMG.

\section{JAILEILA ARAỨJO MENEZES}

http://orcid.org/0000-0003-3322-3764

É docente vinculada ao Departamento de Psicologia e Orientações Educacionais do Centro de Educação e ao Programa de Pós-graduação em Psicologia do Centro de Filosofia e Ciências Humanas da Universidade Federal de Pernambuco. Pesquisadora do Grupo de Estudos e Pesquisas sobre Poder, Cultura e Práticas Coletivas (GEPCOL).

Endereço: Avenida da Arquitetura, s/n. Cidade Universitária. Recife-PE. CEP 50.740-550.

E-mail: jaileila.araujo@gmail.com

\section{SAIANE SILVA LINS}

https://orcid.org/0000-0003-3880-8307

É estudante do curso de graduação em Psicologia da Universidade Federal do Ceará.

E-mail: saianelins@gmail.com

\section{JULIANA VIEIRA SAMPAIO}

https://orcid.org/0000-0001-5770-244X

É docente do curso de Psicologia da Universidade Estadual do Ceará.

E-mail: julianavsampaio@hotmail.com 


\begin{tabular}{ll}
\hline Histórico & Submissão: 17/01/2018 \\
& Revisão: 15/02/2019 \\
& Aceite: 14/03/2019 \\
& Concepção: JAM; JVS; SSL. \\
& Coleta de dados: JAM; JVS; SSL; \\
& Análise de dados: JAM; JVS; \\
& Elaboração do manuscrito: JAM; JVS; SSL. \\
Crítico revisões de conteúdo intelectual importante: & JAM; JVS. \\
Contribuição dos autores & Final aprovação do manuscrito: JAM; JVS; SSL. \\
& $\begin{array}{l}\text { Edital O3/2016 para Bolsista PNPD/Capes do Programa } \\
\text { de Pós-graduação em Psicologia da Universidade Federal } \\
\text { do Ceará para estágio pós-doutoral concedida à Jaileila }\end{array}$ \\
Financiamento & Araújo Menezes. \\
Consentimento de uso de & Não se aplica \\
imagem & Não se aplica \\
$\begin{array}{l}\text { Aprovação, ética e } \\
\text { consentimento }\end{array}$ &
\end{tabular}

